\title{
MARKET INFORMATION AND THE ELITE LAW FIRM
}

\author{
Elisabeth de Fontenay*
}

\begin{abstract}
As a subcategory of contract negotiations, corporate transactions present information problems that have not been fully analyzed. In particular, the literature does not address the possibility that parties may simply be unaware of value-increasing transaction terms or their outside option. Such unawareness can arise even for transactions that attract many competing parties, if the bargaining process is such that (1) the price terms are negotiated and fixed prior to the non-price terms, contrary to the standard assumption; and (2) some of the non-price terms remain private for some period of time.

A simple bargaining model shows that, when such unawareness is reasonably probable, each transaction party will maximize its expected payoff by acquiring current market information about non-price transaction terms. Because they have unique access to it, law firms with a significant share of transactional advisory work play an important role in aggregating and selling such market information. The implication is that, absent shocks to transactional practice, the volume advantage of high-market-share law firms should be self-perpetuating. This result is consistent with the observation that the legal advisory market for major corporate transactions is highly concentrated, and that the top firms earn substantial and persistent rents.
\end{abstract}

* Associate Professor, Duke University School of Law (defontenay@law.duke.edu). Thanks are due to Jennifer Arlen, Ryan Bubb, Albert Choi, Catherine de Fontenay, Deborah DeMott, Josh Fischman, Mitu Gulati, Eric Rasmusen, Barak Richman, Steven Schwarcz, and workshop participants at the American Law and Economics Association's 2016 annual meeting, Duke University's Fuqua School of Business, Duke University School of Law, Harvard Law School, Notre Dame Law School, NYU School of Law, Stanford Law School, Wharton School of the University of Pennsylvania, and Yale Law School. Steven Xie provided outstanding research assistance. All errors are mine. 


\section{INTRODUCTION}

Major corporate transactions such as mergers and acquisitions or financings are characterized by several salient facts that lack a complete theoretical account. First, they are almost universally negotiated at least in part through agents. Transactional lawyers do not simply translate the parties' bargain into legally enforceable language; rather, they are actively involved in proposing and bargaining over the transaction terms (Coates, 2001). Second, such transactions are negotiated in stages, often with the price terms set first by the parties, followed by negotiations primarily among lawyers over the nonprice terms (Choi and Triantis, 2012, p. 1690). Third, while the transaction terms tend to be tailored to the individual parties, in negotiations the parties frequently resort to claims that specific terms are (or are not) "market" (Choi and Triantis, 2013). Fourth, the legal advisory market for such transactions is highly concentrated, with a half-dozen firms holding a majority of the market share (de Fontenay, 2015, p. 402-403).

This paper provides a theoretical account of negotiations over corporate transactions consistent with these facts, centered on specific information problems faced by the parties. The claim is that, for complex transactions experiencing either sustained innovation in terms or rapidly changing market conditions, (1) the parties will maximize their expected surplus by investing in market information about transaction terms, even under relatively competitive conditions, and (2) such market information can effectively be purchased by hiring law firms that hold a significant market share for a particular type of transaction.

The considerable complexity of corporate transaction terms creates an information problem that, to the author's knowledge, has not been addressed in the law or finance literatures: one or both parties may simply be unaware of the complete set of surplus-increasing terms for the transaction and of their respective outside options, should negotiations break down. This problem is distinct from the commonly treated problem of valuation uncertainty. Rather than unawareness of facts that may affect the value of the capital asset to be transferred between the parties, the problem identified here is unawareness of the possibilities for contracting with respect to that asset. The difference can be illustrated using the well-worn example of a used-car sale. The buyer may be uncertain as to the value of the car itself, given unawareness of certain facts such as whether it was well maintained by the seller. This source of valuation uncertainty can be mitigated in part by a seller-provided warranty. A different problem is presented, however, if the parties are entirely unaware of the concept of a warranty.

Though unrealistic in the context of used-car sales, both unawareness of value-increasing terms and uncertainty over outside options are not only plausible, but likely for certain corporate transactions. The non-price terms of 
transactional agreements and their associated payoffs may change rapidly as a result of contractual innovation and market conditions (Choi and Triantis, 2013), such that parties without current market information may have difficulty determining their expected surplus from transacting. This is particularly so for corporate transactions involving private companies or private securities offerings that are not otherwise subject to public disclosure requirements, because the transaction terms will remain private for at least some period of time. In such cases, law firms with a high market share of that particular advisory work are likely to have the best real-time access to the full range of transaction terms, given their role in negotiations and control of the transaction agreements.

This unawareness problem can exist even for transactions in which large numbers of participants compete to be matched. This is because many corporate transactions are negotiated in the reverse order from that assumed by standard bargaining models. In such transactions-which include most mergers and acquisitions and loan financings - the price term is set first in a process (such as an auction) that is at least potentially open to many participants. Once the party offering the best price at this stage has been identified and selected, the matched counterparties proceed to negotiate the bulk of the non-price terms on a bilateral basis, typically with their respective lawyers taking the lead (Manns and Anderson, 2013, p. 1176; Choi and Triantis, 2012, p. 1690-91). Although the price term is set in the first stage with some expectation as to what the final non-price terms will be, the latter are not fully specified $e x$ ante, due to the transaction costs and delay involved with negotiating hundreds of complex transaction terms with every potential bidder. As a result, a party lacking complete information about non-price transaction terms cannot count on being offered the "market" terms purely through competition among its potential counterparties.

The parties to such transactions are therefore in a strategic game: they must decide whether to invest in acquiring market information about transaction terms and how much of this information to reveal to their counterparty. The bilateral bargaining model herein shows that, under plausible assumptions, there is a unique Nash equilibrium to the parties' game in which both sides will engage an "informed" law firm to advise them on the transaction. This joint investment in market information ensures that the parties will get the benefit of all value-increasing transaction terms, while avoiding costly signals to an uninformed counterparty.

The implication is that aggregating and selling market information can be important roles for law firms with leading transactional practices, as distinguished from their traditional roles as reputational intermediaries, regulatory experts, and draftsmen. Such law firms should therefore have a selfperpetuating volume advantage for transactions in which a material share of the information about transaction terms is private. The paper thus contributes 
to the literature on the role of lawyers in corporate transactions (Coates, 2001; Gilson, 1984; Kraakman, 1986; Schwarcz, 2007; Ribstein, 2010, Krishnan and Masulis, 2013). Finally, the paper has broad implications for contract theory. The dominant view is that the non-price terms of voluntary bargains will tend to be efficient - that is, they will be surplus-maximizing for the parties taken collectively (Priest, 1981; Schwartz, 1977). The paper shows that institutional differences in how transactional agreements are negotiated can lead the parties to deviate from the efficient set of terms, simply by being unaware of the surplus-maximizing set, for example. Moreover, because transactional lawyers typically drive negotiations over the non-price terms, they ultimately play a far greater role in valuing transaction terms than is commonly understood.

Section 2 briefly reviews the literature on information problems in corporate transactions and introduces the problem of unawareness of the scope and pricing of transaction terms. Section 3 explains law firms' role in aggregating current market information about transaction terms and the conditions under which market information may be valuable for transactional bargaining. Section 4 presents a game-theory model of law firm selection in transactional bargaining. For transactions involving a reasonable probability of unawareness, the parties are incentivized to select law firms with market information. Section 5 concludes.

\section{Information Problems in CORPORATE TransaCtions}

Negotiations over the terms of major corporate transactions such as mergers and acquisitions or financings are an instance of bargaining under incomplete and asymmetric information. First, if we define such transactions simply as transfers of capital assets (Gilson, 1984), the parties are likely to face uncertainty about the value of that asset, and relevant information is likely to be asymmetrically distributed between them (ibid.). In negotiating the sale of a company, for example, the seller should have better information than the buyer as to the company's value. Similarly, in the case of financing transactions, investors know less than management about the firm's quality and management's potential for moral hazard.

Corporate lawyers play an important role in mitigating such informational asymmetries in valuation. First, they draft contract terms that allow for signaling and screening (ibid.). Terms such as earnouts and indemnification provisions shift some of the valuation risk to the more informed party. Representations and warranties serve not only as a risk-shifting device, but also as a means of inducing the more informed party to disclose information relevant to valuation. In financing contracts, the various covenants agreed to by the borrower also serve to limit moral hazard (Smith and Warner, 1979). This contractual approach to mitigating information asymmetry has been referred to as "transaction cost engineering" (Gilson, 1984). Second, law firms 
can mitigate information asymmetry over valuation by acting as reputational intermediaries (Kraakman, 1986; Okamoto, 1995). Being represented by a well-established law firm could signal some level of quality to the market, based on the law firm's reputation for due diligence, for example, or the private information that it has acquired over the course of its longstanding representation of the company. ${ }^{1}$

Yet the information problems faced by the parties are not limited to uncertainty over the value of the capital asset to be transferred between them. The agreements governing such transfers are highly complex, generally comprising hundreds of substantive terms, many of which are heavily negotiated among the counterparties (Coates, 2001). This complexity appears to be primarily driven by three factors, among many others. First, as discussed, firm valuation is notoriously uncertain, and the parties use an array of transaction terms to transfer valuation risk between them. Second, corporate transactions and corporate operations may be subject to complex regulation affecting both value and process in corporate transactions, which in turn is reflected in transaction agreements (Schwarcz, 2007; Fleischer, 2010). Third, corporate transactions do not occur all at once. They unfold in several stages (such as signing, closing, and the post-closing indemnification period), and they often establish an ongoing relationship between the parties (such as with credit facilities), adding risk and uncertainty for the parties.

This complexity of corporate transaction terms creates additional information problems for the parties. To maximize their joint surplus, the parties must successfully identify the complete set of value-increasing terms for the transaction at issue. The parties thus require information not only about the value of the capital asset at issue, but also about the myriad possibilities for contracting with regards to that asset, and the latter may be difficult to obtain. Specifically, one or both parties (1) may be unaware of the existence of terms that would be value-increasing and (2) may lack information as to the value of their respective outside options, should negotiations break down.

Consider each of these in turn. Unawareness of value-increasing terms can occur most obviously if new terms are frequently being devised for a particular type of transaction, but remain private for at least some period of time. While many transaction terms become standardized over time (Choi and Gulati, 2006; Kahan and Klausner, 1997), it is also the case that new terms do arise, and specific transaction types in specific periods have experienced high rates of contractual innovation (de Fontenay, 2015). Financial innovation, regulatory change, technological change, and changes in market conditions can all prompt contractual innovation. Because such innovations may not become public

\footnotetext{
1 The signal (if any) provided by law-firm reputation is likely to be considerably weaker today than during eras in which clients commonly maintained long-term relationships with a single law firm (Gilson, 1991).
} 
knowledge for some time (as discussed below), transaction parties that are not high-volume players are likely to remain unaware in the meantime. ${ }^{2}$

Second, parties may lack sufficient information to determine the expected payoffs from various transaction terms or the overall value of their outside option. This is so even in the absence of any innovation in transaction terms, because payoffs can vary based on market conditions, regulatory changes, or the specific characteristics of the parties. Imagine, for example, a buyer that intends to rely heavily on debt-financing to acquire another company. As the parties negotiate the acquisition agreement, the value of the buyer's right to terminate the agreement if it fails to obtain financing will depend largely on the condition of the credit markets between signing and closing.

In sum, the set of surplus-maximizing terms for a particular transaction and their associated payoffs can vary considerably over time and for different parties. Section 3 explains why information about transaction terms can increase a party's payoff in expectation and where such information can be obtained.

\section{MARKET INFORMATION: WhERE TO GET IT AND WHY}

We refer here to current information about the terms of a particular type of corporate transaction as "market information." At a minimum, it consists of real-time knowledge of the complete set of final terms of recent comparable transactions-effectively, a database of transaction documents for the most recently completed deals. At its best, it further includes experience with negotiating such terms, sufficient to enable a rough estimation of the expected payoffs of such terms to similar parties and their pricing under current market conditions. ${ }^{3}$

As we have seen, for certain transactions market information may be private for at least some period of time. It is therefore at least partially excludable. But does it necessarily have value? In a relatively competitive market, we would assume that, regardless of a party's knowledge of the transaction terms obtained by others, it would be offered the "market" terms in equilibrium. This need not be the case, however. Many types of corporate transactions are negotiated in such a way that the parties' information about

2 Unawareness was first formalized in economic theory by Fagin and Halpern (1988). General models for strategic interaction with unawareness and their solution concepts are found in Feinberg (2004), Li (2006), Heifetz, Meier and Schipper (2006, 2008), Grant and Quiggin (2009), and Halpern and Rego (2006), among others. Feinberg (2012) proves the existence of the extended Nash equilibrium solution for dynamic games with unawareness, defined as games involving players with different and limited perceptions of the game.

${ }^{3}$ In practice, rather than being able to assign specific dollar values to various transaction terms, transactional lawyers are likely to develop an intuitive sense of the relative value of different transaction terms to the parties. Their role in negotiations is thus to ensure that the client trades off terms of equivalent value. 
the market and expected payoffs from individual terms should affect both the amount of surplus from the transaction and its distribution between the counterparties.

The principal reason is that, as discussed, transactions such as mergers and acquisitions and loan financings are negotiated in stages. In the first stage, the price terms and a subset of key non-price terms are agreed upon by the principals and often captured in the form of a term sheet, letter of intent or commitment letter. In the second stage, the remainder of the non-price terms are negotiated bilaterally, primarily between the parties' legal counsel. While the price terms agreed to in the first stage tend to be public knowledge, for certain types of transactions some or all of the non-price terms agreed to in later stages can remain private for an extended period of time, as we have seen. Importantly, the price terms agreed to in the first stage-which typically become public knowledge-are sticky, regardless of the bargain reached in the later stages with respect to the remaining terms (Manns and Anderson, 2013, p. 1176; Choi and Triantis, 2012, p. 1690-91). In other words, notwithstanding that the parties' agreement with respect to the price terms is rarely, if ever, legally binding, the parties are highly unlikely to modify the public price terms once they have been fixed.

This form of negotiation represents a puzzle for the traditional law and economics literature, which assumes that the price term is set last, such that any horse-trading over non-price terms is simply reflected in a corresponding adjustment to the price term. Why indeed would the parties risk breaking off negotiations entirely over disagreements with respect to the non-price terms, rather than simply adjust the price term? The explanation appears to turn on ex ante efficiency considerations in the negotiation process and repeat-player reputational dynamics, which combine to create a strong norm against renegotiating the price term. Negotiating the non-price terms of a transaction is a complex, time-consuming affair. The investment in time and money is unlikely to be recouped unless the parties are relatively confident that they have a deal. Thus, the business teams will begin by agreeing to the price terms and a subset of non-price terms, subject to a non-binding understanding that, in the later stages of negotiations, the remaining non-price terms will be in the range of the appropriate "market" terms, adjusted for the particularities of the transaction and the counterparties at issue.

This two-stage approach is particularly justified when the counterparties to the deal have not been predetermined. For example, a company putting itself up for sale will often run an auction with multiple bidders, in order to achieve the highest price in the shortest amount of time. In most cases, negotiating a complete and binding merger agreement with each of the potential bidders would involve excessive transaction costs and delay. Instead, then, the auction can be limited to the price term(s) and a key subset of non-price terms, leaving the remainder of the terms to be negotiated by counsel once the winning 
bidder has been selected. Thus, while multiple bidders compete to offer the best price term, negotiations over the bulk of the non-price terms occur exclusively between two parties.

In this two-stage approach, it is therefore crucial to have current information about the market non-price terms, since the latter will not simply be offered by bidders competing against one another. Intuitively, then, if the parties can invest in market information and the cost is less than the expected benefit, they will do so. Section 4 provides a theoretical demonstration of this intuition. As we shall see, the information game in this case is strategic, given that each party's expected payoff from the transaction will depend also on the counterparty's information.

A ready solution is simply to engage one of the law firms that holds a significant share of the advisory market for the type of transaction at issue. Not only do such firms have access to the final transaction agreements for recent deals, they have acquired additional private information about the relative payoffs and pricing of transaction terms by haggling over them. ${ }^{4}$ While other market participants such as investment banks also acquire market information about transaction terms, law firms should have the most complete information about non-price terms, due to their role in all stages of negotiations and their control of the transaction documents.

\section{Model of LAW Firm SELECTion}

\section{A. Bargaining Framework.}

The parties, described generally as "borrower" and "lender," are to negotiate the terms of a private transaction (the "loan"). The price terms of such loans are common knowledge, while the non-price terms are private information. Prior to the negotiations, each party must decide whether to engage — at higher cost — a law firm that is informed of the market terms for such loans.

The set of transaction terms to be negotiated consists of:

(1) a price term $\mathbf{p}$ (such as the interest rate and fees on a loan);

(2) discrete non-price terms; and

(3) for convenience, a continuous term $\mathbf{t}$ that both parties value comparably.

The continuous term $t$ is equivalent to a straight transfer between the parties. ${ }^{5}$ A positive (negative) value of $t$ represents a transfer from the borrower (lender) to the lender (borrower). We assume that the value of $t$ in earlier

\footnotetext{
4 This haggling may also take place in post-closing litigation handled by the same firm, in which the parties fight over the value of terms in settlement discussions.

${ }^{5}$ In practice such a continuous variable may not exist, but could be approximated by aggregating several different terms with small costs and benefits.
} 
periods was negotiated to be $t=0$-it is set to zero without loss of generality - and that this is common knowledge.

Assume that there exists a discrete term $\mathbf{d}$ that is not yet common knowledge. For a borrower of this type, $d$ would benefit the borrower at the lender's expense, but is value-increasing overall: that is, if included in the transaction agreement, the discrete term would increase the borrower's expected payoff by an amount $\boldsymbol{x}>0$ and decrease the lender's expected payoff by an amount $\boldsymbol{y}>0$, but with $x-y>0$. Assume that both parties can fully calculate the expected benefits and costs of this discrete term once they are made aware of it. ${ }^{6}$

The transaction negotiations occur in three stages, reflecting the practice for certain corporate transactions of settling on the price terms before negotiating the non-price terms:

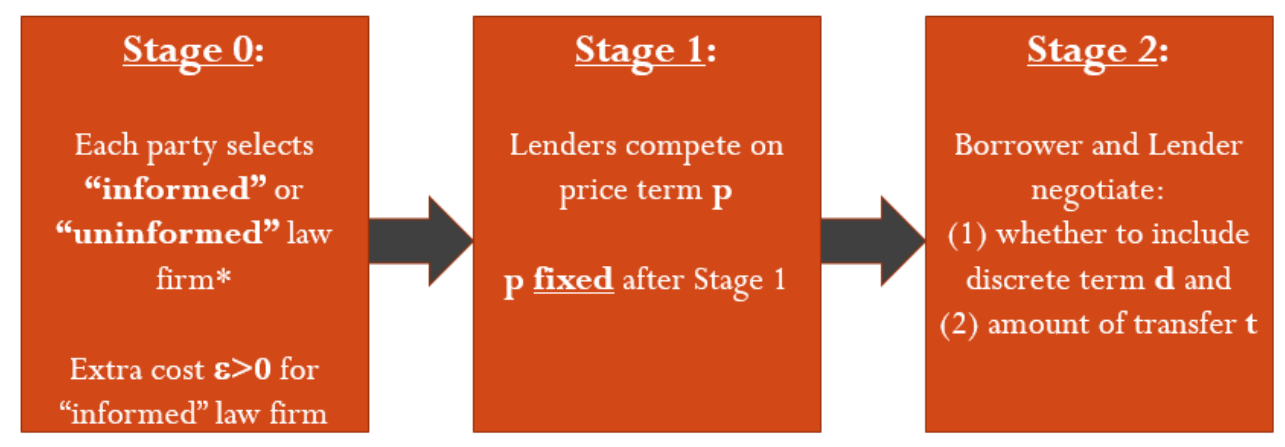

$\underline{\text { Stage 0: }}$ Each party simultaneously chooses whether to hire an "informed" law firm (defined below) or an "uninformed" law firm. Because of reputation effects in these markets, it is common knowledge which law firms are informed, such that each party will know whether the other is informed when they begin negotiating non-price terms in Stage 2. Informed law firms are more expensive, represented here by an additional fixed $\operatorname{cost} \boldsymbol{\varepsilon}>0$; therefore, they will not be used unless there is an expected benefit to the client.

Stage 1: Lenders compete in an auction to offer the borrower the lowest price term. The price that lenders are willing to offer reflects what they expect to negotiate as non-price terms in Stage 2. Because the price term is publicly observable for these loans, all parties are aware of what the likely price term is for a borrower with these characteristics. The borrower selects the lender offering the lowest price term. Once the winning lender has been selected, per

\footnotetext{
${ }^{6}$ As discussed above, in practice the parties may also be uncertain as to their expected payoff from the discrete term, particularly if it is a relatively novel term. An informed law firm's market information should mitigate this source of uncertainty as well, though this is not modeled here.
} 
market practice the agreed-upon price term may not be changed during subsequent negotiations.

Stage 2: The parties negotiate the remaining transaction terms. The negotiation is limited to (i) deciding whether to include the discrete term $\mathbf{d}$ in the transaction agreement (if at least one party is aware of it) and (ii) setting the transfer payment $\mathbf{t}$. Negotiations proceed according to the alternating-offers protocol outlined by Binmore, Rubinstein and Wolinsky (1986). After any offer is rejected, there is a very small chance $(1-\boldsymbol{\delta})$ that the negotiation will exogenously break down (that is, $0<\delta<1$ and $\delta$ is very close to 1 ). In that event, both parties incur a lump-sum loss $\mathbf{L}$ and return to the market. ${ }^{7}$ (In practice, L might represent breach of contract damages, pre-negotiated termination fees, or the transaction costs associated with beginning the process all over again with another party.) In this type of game, the parties negotiate over a split of the surplus, defined as the total payoff to agreement minus the payoff from the parties' outside options (Sutton, 1986). Assuming here no difference in negotiating skill between informed and uninformed law firms, the equilibrium outcome of the negotiation is that the parties will simply split the surplus equally (ibid.).

Consistent with reports by practitioners, we posit that, over time, the nonprice terms of a transaction agreement can temporarily shift in favor of one or the other party. ${ }^{8}$ Without loss of generality, we initially consider the case in which the non-price terms have shifted in favor of borrowers in the form of the discrete term $\mathrm{d}$. In other words, if both parties were fully informed, the most likely set of loan terms to be offered a borrower with these specific characteristics by any lender (the "market" terms) would be (1) a price term of $\mathrm{p}$, (2) the discrete term $\mathrm{d}$, and (3) no transfer payment $(\mathrm{t}=0)$. This set of terms is referred to as the "Borrower-Friendly" loan agreement.

By contrast, if both parties are uninformed (and therefore unaware of both the discrete term $\mathrm{d}$ and the market shift in borrowers' favor), they expect that borrowers of this type are being offered loan agreements with (1) a price term

\footnotetext{
${ }^{7}$ For simplicity, both parties incur the same loss L here, but the model's results hold if the parties incur different loss amounts.

${ }^{8}$ Choi and Triantis (2013) show that where, as here, the price term is set first in multistage negotiations, the parties' relative bargaining power can affect the non-price terms to which they will agree. (The model herein assumes equal bargaining power.) Yet multi-stage negotiations could also lead to temporary market-wide shifts in non-price terms in favor of one side of a transaction. When signs of a major credit crunch first manifested in the summer of 2007, for example, the largest U.S. banks had already committed to provide billions of dollars in financing for new leveraged buyout transactions at historically low interest rates. Because the borrower-favorable "price term" had previously been fixed, the shift in market conditions - the tightening of credit-resulted in lender-favorable non-price terms marketwide when the loan terms were eventually negotiated.
} 
of $\mathrm{p},(2)$ no additional discrete terms, and (3) no transfer payment $(\mathrm{t}=0)$. We define $\boldsymbol{\pi}_{\boldsymbol{b}}$ and $\boldsymbol{\pi}_{\boldsymbol{l}}$ as the payoffs to the borrower and the lender, respectively, under this "Neutral' loan agreement.

An "informed" law firm is thus both (1) aware of the discrete term $\mathbf{d}$ and its associated payoffs for the parties and (2) aware that the parties' outside option is currently the Borrower-Friendly loan agreement. By contrast, an "uninformed" law firm (1) is not aware of the discrete term $\mathrm{d}$ and (2) mistakenly believes that the parties' outside option is the Neutral loan agreement.

The outcomes at Stage 1 and 2 generate the payoffs for the following choices at Stage 0:

Fig. 1. Stage 0: Selection of Law Firms.

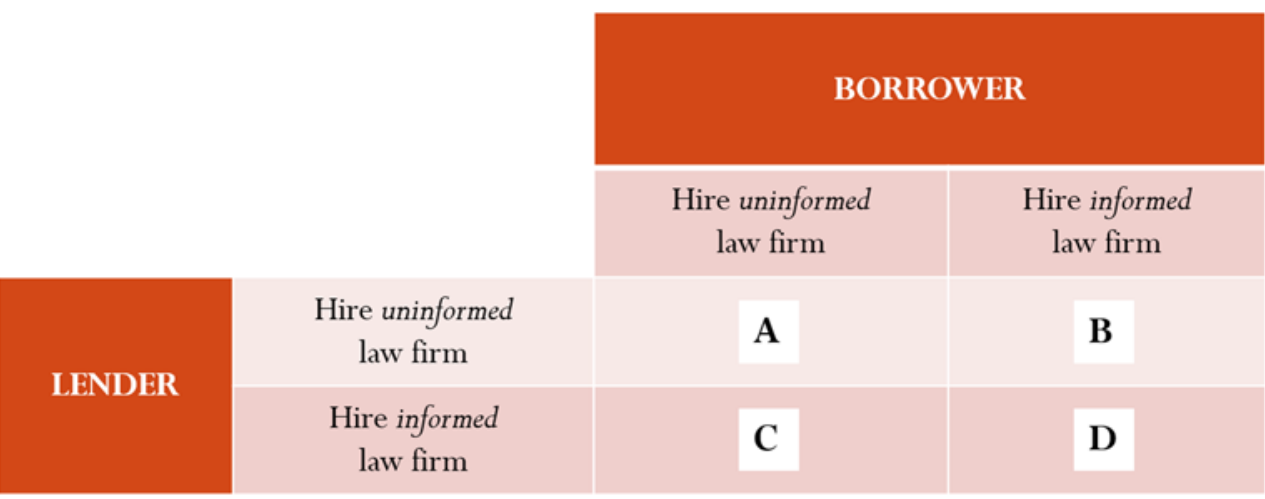

We show below that State D is the unique Nash equilibrium of this game: both parties benefit in Stage 2 from being represented by an informed law firm. By implication, as long as $\varepsilon$ is small enough, both parties will hire informed law firms at Stage 0 .

\section{B. Proof.}

Suppose that all lenders offer a price term near $\mathrm{p}$ at Stage 1. The borrower selects one such lender and we now consider outcomes at Stage 2, in which the non-price terms are negotiated bilaterally. ${ }^{9}$

1. State A: Both parties uninformed.

Because neither party's law firm is informed in State A, both parties are unaware of the discrete term d; thus it does not feature in the negotiation.

\footnotetext{
${ }^{9}$ Because the additional cost of using an informed law firm is modeled here as a lump sum, it is sunk at Stage 2 and need not be considered.
} 
Instead, they negotiate over the level of the continuous term, t. Recall that their final payoffs will be $\left(\pi_{b}-t\right)$ and $\left(\pi_{l}+t\right)$, respectively, and $\mathrm{t}$ may be negative. What value of $t$ is agreed upon in equilibrium? The parties expect that in every other negotiation, parties are agreeing to the Neutral terms (no additional discrete terms and $\mathrm{t}=0$ ), which provide payoffs to the borrower and lender of $\pi_{b}$ and $\pi_{l}$ respectively. And they value their outside options at $\left(\pi_{b}-L\right)$ and $\left(\pi_{l}-L\right)$, respectively, where $L$ is the lump-sum loss incurred in the event the negotiations break down. The negotiated value of $t$ is determined by the parties' splitting the surplus equally:

$$
\begin{gathered}
\text { Borrower's surplus }=\text { Lender's surplus } \\
\left(\pi_{b}-t\right)-\left(\pi_{b}-L\right)=\left(\pi_{l}+t\right)-\left(\pi_{l}-L\right) \\
\rightarrow t=0
\end{gathered}
$$

Thus, assuming evenly matched bargaining skill, the two parties simply agree to what they (incorrectly) believe is the market loan agreement, namely the Neutral agreement. The payoffs are $\pi_{b}$ and $\pi_{l}$ to the borrower and lender, respectively.

2. State C: Informed lender; uninformed borrower.

In State C, the law firm representing the lender is informed, while the borrower's law firm is uninformed. Because the discrete term $\mathrm{d}$ is surplusincreasing overall (albeit costly to the lender), the lender will reveal the term to the borrower and offer to include it in their agreement, in exchange for an appropriate transfer payment $\mathrm{t}$. However, the lender will not reveal that the borrower's outside option is Borrower-Friendly (i.e., that it includes the discrete term $\mathrm{d}$ with $\mathrm{t}=0$ ). The parties will therefore negotiate as though the outside option is Neutral (i.e., no additional discrete terms and $\mathrm{t}=0$ ). The bargaining will lead to a transfer payment from the borrower to the lender, since the borrower benefits more from the discrete term:

$$
\begin{gathered}
\text { Borrower's surplus = Lender's surplus } \\
\left(\pi_{b}+x-t\right)-\left(\pi_{b}-L\right)=\left(\pi_{l}-y+t\right)-\left(\pi_{l}-L\right) \\
x+y=2 t \\
t=0.5(x+y)
\end{gathered}
$$

The associated payoffs are $\pi_{b}+0.5(x-y)$ to the borrower and $\pi_{l}+$ $0.5(x-y)$ to the lender, respectively.

3. State D: Both parties informed. 
In State D, both law firms are informed: they are aware of the discrete term and aware that the outside option is Borrower-Friendly. They always find it optimal to negotiate an efficient agreement- that is, one in which the discrete term is included. (Even if the lender had all the bargaining power, it would include the discrete term in exchange for additional payment of $t=(x-y)$.) The negotiated value of $\mathrm{t}$ is determined by the parties' outside options: the losses $\mathrm{L}$ from breaking off negotiations and the payoffs $\left(\pi_{b}+x\right)$ and $\left(\pi_{l}-\right.$ $y$ ), respectively, that the parties expect to earn if they negotiate with other parties:

$$
\begin{aligned}
& \text { Borrower's surplus }=\text { Lender's surplus } \\
& \begin{array}{c}
\left(\pi_{b}+x-t\right)-\left(\pi_{b}+x-L\right)=\left(\pi_{l}-y+t\right)-\left(\pi_{l}-y-L\right) \\
\rightarrow \quad t=0
\end{array}
\end{aligned}
$$

The associated payoffs are $\pi_{b}+x$ to the borrower and $\pi_{l}-y$ to the lender, respectively. Thus, if the lender is informed, the borrower improves its payoff by also becoming informed (moving from State C to State D).

4. State B: Informed borrower; uninformed lender.

In State B, the borrower's law firm is informed but the lender's is not. The borrower's firm asserts that the market loan agreement is the Borrower-Friendly agreement. To make this self-serving claim credible, however, the borrower must signal through costly delay in the negotiations (Admati and Perry, 1987). Suppose that the lender will believe the claim after the borrower has rejected $\mathbf{n}$ offers made by the lender, and had $\mathbf{n}$ offers of its own rejected. Thus, after $2 \mathrm{n}$ rejections, the parties will agree to the Borrower-Friendly agreement (the discrete term and $\mathrm{t}=0$ ). To make the claim credible, $\mathrm{n}$ must be sufficiently high that a non-credible party is worse off for having rejected that many offers. Thus, $\mathrm{n}$ must be such that it would be unprofitable to wait $2 \mathrm{n}$ periods if the true market loan agreement were actually the Neutral agreement (no discrete term and $\mathrm{t}=0)$.

If instead the market loan agreement were the Neutral agreement, the parties would negotiate a loan agreement that nonetheless included the discrete term d (since it is surplus-increasing overall and the borrower is aware of it) but that set $\mathrm{t}$ to reflect that the borrower's and the lender's respective outside options did not include the discrete term. The resulting deal would be:

$$
\begin{gathered}
\text { Borrower's surplus }=\text { Lender's surplus } \\
\begin{array}{c}
\left(\pi_{b}+x-t\right)-\left(\pi_{b}-L\right)=\left(\pi_{l}-y+t\right)-\left(\pi_{l}-L\right) \\
x+y=2 t \\
t=0.5(x+y)
\end{array}
\end{gathered}
$$


Revealing the new term to the lender in this case would therefore earn the borrower an additional $x$, but also cost it $t=0.5(x+y)$. This is referred to hereafter as the "Default" Agreement.

Instead, the borrower wishes to signal that the market loan agreement is the Borrower-Friendly agreement. To constitute a credible signal, n must be such that the payoff to a borrower sending a false Borrower-Friendly signal through $2 \mathrm{n}$ offers is less than if the borrower simply accepts the Default agreement from the outset:

Payoff to sending false Borrower-Friendly signal through 2n offers $<$ Payoff to accepting Default

$$
\begin{gathered}
\left(\begin{array}{c}
\text { Payoff if } \\
\text { negotiations } \\
\text { continue through } \\
2 \mathrm{n} \text { rejections }
\end{array}\right)+\left(\begin{array}{c}
\text { Payoff if } \\
\text { negotiations } \\
\text { break down before } \\
2 \mathrm{n} \text { rejections }
\end{array}\right)<\text { Payoff to accepting Default } \\
\delta^{2 n}\left(\pi_{b}+x\right)+\left(1-\delta^{2 n}\right)\left(\pi_{b}-L\right)<\pi_{b}+x-0.5(x+y) \\
n>\frac{[\ln (L+0.5(x-y))-\ln (L+x)]}{2 \ln (\delta)}
\end{gathered}
$$

Thus, there is some $\mathrm{n}$ for which non-credible borrowers are screened out. If we choose the smallest value of $\mathrm{n}$ for which the inequality holds for a noncredible borrower, then the inequality will not hold for an informed borrower signaling credibly. In that case, if the market agreement is truly the BorrowerFriendly agreement, then $\mathrm{n}$ is such that:

Payoff to sending true Borrower-Friendly signal through 2n offers

$$
>\text { Payoff to accepting Default }
$$

$$
\begin{gathered}
\left(\begin{array}{c}
\text { Payoff if } \\
\text { negotiations } \\
\text { continue through } \\
2 \mathrm{n} \text { rejections }
\end{array}\right)+\left(\begin{array}{c}
\text { Payoff if } \\
\text { negotiations } \\
\text { break down before } \\
2 \mathrm{n} \text { rejections }
\end{array}\right)>\text { Payoff to accepting Default } \\
\delta^{2 n}\left(\pi_{b}+x\right)+\left(1-\delta^{2 n}\right)\left(\pi_{b}+x-L\right)>\pi_{b}+x-0.5(x+y) \\
\delta^{2 n}\left(\pi_{b}+x\right)+\left(1-\delta^{2 n}\right)\left(\pi_{b}+x-L\right)>\pi_{b}+0.5(x-y)
\end{gathered}
$$


Thus, in State B (in which an informed borrower faces an uninformed lender), the borrower's payoff-the left side of inequality (1)—is strictly greater than the borrower's payoff in State $\mathrm{C}$ (an uninformed borrower facing an informed lender) — the right side of inequality (1). The borrower's payoff has also increased relative to State A in which both parties uninformed: it has increased from $\pi_{b}$ to something above $\left(\pi_{b}+0.5(x-y)\right)$, which is greater.

Separately, the lender's payoff increases when moving from State B to D. The lender's payoff in State B is $\delta^{2 n}\left(\pi_{l}-y\right)+\left(1-\delta^{2 n}\right)\left(\pi_{l}-y-L\right)$. That is, the lender will accept a payoff of $\left(\pi_{l}-y\right)$ after signaling, but there is some risk that the negotiations break down during the credible signaling phase. If the negotiations break down, the lender returns to the market, incurs loss L, and learns that the market terms are $\left(\pi_{l}-y\right)$. The lender's payoff in State $\mathrm{D}$ is $\left(\pi_{l}-y\right)$, which is greater than in State B, because the lender avoids the risks of the signaling process. Formally:

$$
\begin{aligned}
& \begin{aligned}
\text { Lender's payoff in } \mathrm{B}=\delta^{2 n}\left(\pi_{l}-y\right) & +\left(1-\delta^{2 n}\right)\left(\pi_{l}-y-L\right) \\
=\pi_{l}-y-L\left(1-\delta^{2 n}\right) & \\
& <\pi_{l}-y
\end{aligned} \\
& \text { because }\left(1-\delta^{2 n}\right)>0 \text {, given that } 0<\delta<1 .
\end{aligned}
$$

Fig. 2. Payoffs at Stage 2, if the market terms have shifted in favor of borrowers, and there is a surplus-increasing discrete term. ${ }^{10}$

\footnotetext{
${ }^{10}$ In each cell, the top entry represents the payoff to the lender, while the bottom entry represents the payoff to the borrower.
} 


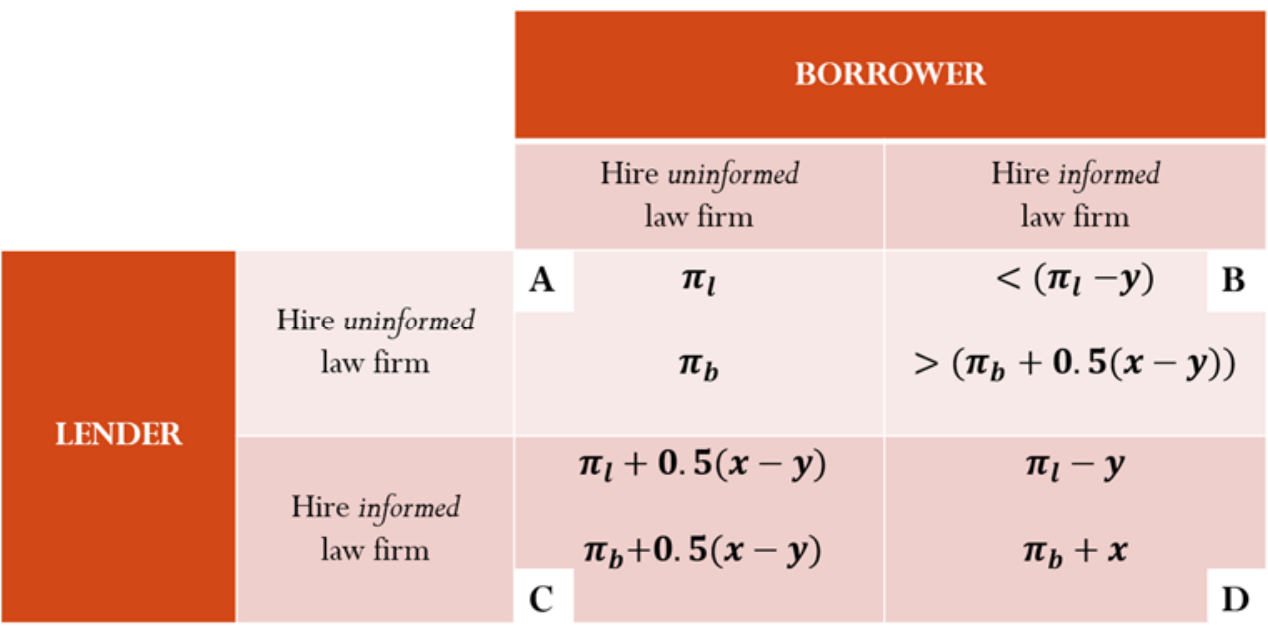

Stage 0 decision: In Stage 0, the parties must choose whether to hire an informed law firm or an uninformed law firm. They choose based on the probability that market terms have shifted in favor of one party or the other, and the probability that surplus-enhancing discrete terms exist.

In the scenario summarized in Figure 2, in which the market terms are favorable to borrowers, there is a strict ordering of preferences: borrowers prefer $\mathrm{B}$ to $\mathrm{A}$, and $\mathrm{D}$ to $\mathrm{C}$; and lenders prefer $\mathrm{C}$ to $\mathrm{A}$, and $\mathrm{D}$ to $\mathrm{B}$.

By a parallel argument, if the market terms had instead shifted in favor of lenders, and a surplus-enhancing discrete term existed, the identical preference ranking of states would hold. In this case, the lender would credibly signal to the borrower in state $\mathrm{C}$. In state $\mathrm{B}$, the borrower would inform the lender of the discrete term, but not of the market shift, and the surplus would be split. State $\mathrm{D}$ would be identical.

The remaining case to be analyzed is where the market terms have shifted in favor of one party, but no new surplus-increasing discrete terms have appeared. (This case is easily derived from the prior calculations: it is the case in which $x=y$.) In that case, the informed party dealing with an uninformed party will credibly signal when terms have shifted in their favor, and otherwise will remain silent. If terms have shifted in favor of borrowers, this means that $\mathrm{A}$ and $\mathrm{C}$ are identical in terms of payoffs to both parties (before considering legal costs). In $\mathrm{B}$, the borrower engages in costly signaling that terms have shifted in borrowers' favor; the result is payoffs similar to $\mathrm{D}$, minus the costs of signaling, which in this case is the increased risk of a breakdown in negotiations. Thus, the borrower prefers $\mathrm{B}$ to $\mathrm{A}$ and $\mathrm{D}$ to $\mathrm{C}$, while the lender prefers $\mathrm{D}$ to $\mathrm{B}$. It follows that $\mathrm{D}$ is the only equilibrium.

Finally, if no market shifts in terms have occurred, and no discrete terms have arisen, the payoff to all states is identical (before considering legal costs).

In Stage 0, the firm considers that all of these scenarios arise with some 
positive probability. As a consequence, so long as $\varepsilon$ (the additional cost of informed law firms) is small enough, outcome D is the only Nash equilibrium. If the parties were at $A$, the borrower would deviate to $B$, as it is preferable in expectation, from which the lender would deviate to $\mathrm{D}$. If the parties were at C, the borrower would deviate to D. Thus, so long as $\varepsilon$ is small enough, both parties will select informed law firms.

\section{ConClusion}

The market for law firms advising on large corporate transactions is highly concentrated, although the firms with the largest market shares vary by transaction type. There are many reasons why corporate clients might engage law firms with significant market share for their transactions. First, law firms that advise on a high volume of transactions can develop expertise relevant to the ultimate transactional outcome. They may become experts at structuring transactions and devising transaction terms to minimize information and transaction costs (Gilson, 1984); optimizing regulatory costs (Schwarcz, 2007); speed and certainty of execution; negotiating strategy, and so forth. Second, high-market-share law firms may provide reputational advantages to transactional clients, providing a certification function for transaction parties similar to auditors (Kraakman, 1986).

This paper describes an additional advantage to a law firm's sizable market share: such firms have privileged access to the terms of recent transactions and expertise in haggling over them. This expertise in market information ensures that clients are aware of the full set of value-increasing terms for their transaction, and enables them to better determine expected payoffs and outside options for the complex non-price terms in major corporate transactions. Assuming a particular transaction type for which (1) the price term is set prior to the negotiation of non-price terms, (2) the non-price terms remain private for some period of time following agreement, and (3) the nonprice terms may temporarily shift in favor of one side without being reflected in the (public) price term, the model demonstrates that both counterparties to the transaction will maximize their expected transaction surplus by engaging a law firm with market information about transaction terms. Thus, elite law firms' role in corporate transactions may extend beyond drafting and even innovating new terms to assisting with the pricing of terms.

The notion that law firms may act as informational intermediaries in corporate transactions has gained broad acceptance over the last few decades (Gilson and Krakman, 1984). Thus far, however, efforts to identify precisely what types of information law firms can acquire, and how such information can improve bargaining outcomes under different negotiating conditions, have been relatively limited. Future research in this area could be devoted to 
determining the relative weight of elite firms' various roles in the profits generated from corporate transactions.

\section{REFERENCES}

Admati, Anat R., and Motty Perry. 1987. "Strategic Delay in Bargaining," 54 Review of Economic Studies 345-364.

Binmore, Ken, Ariel Rubinstein, and Asher Wolinsky. "The Nash Bargaining Solution in Economic Modelling," 17 Rand Journal of Economics 176-188.

Choi, Albert, and George Triantis. 2012. "The Effect of Bargaining Power on Contract Design," 98 Virginia Law Review 1665-1743.

Choi, Albert, and George Triantis. 2013. "Market Conditions and Contract Design: Variations in Debt Contracting," 88 New York University Law Review 5182.

Choi, Stephen J., and G. Mitu Gulati. 2006. "Contract as Statute," 104 Michigan Law Review 1129-1173.

Coates IV, John C. 2001. "Explaining Variation in Takeover Defenses: Blame the Lawyers," 89 California Law Review 1301-1421.

Fagin, Ronald, and Joseph Y. Halpern. 1998. "Belief, Awareness, and Limited Reasoning," 34 Artificial Intelligence 39-76.

Feinberg, Yossi. 2004. "Subjective Reasoning_Games with Unawareness," Stanford, Graduate School of Business, Research Paper No. 1875.

Feinberg, Yossi. 2012. “Games with Unawareness,” Working Paper, August.

Fleischer, Victor. 2010. "Regulatory Arbitrage," 89 Texas Law Review 227-289.

de Fontenay, Elisabeth. 2015. "Law Firm Selection and the Value of Transactional Lawyering," 41 Journal of Corporation Law 393-430.

Gilson, Ronald J. 1984. "Value Creation by Business Lawyers: Legal Skills and Asset Pricing," 94 Yale Law Journal 239-313.

Gilson, Ronald J. 1990. “The Devolution of the Legal Profession: A Demand 
Side Perspective," 49 Maryland Law Review 869-916.

Grant, Simon, and John Quiggin. 2009. "Inductive Reasoning About Unawareness," Rice University, Working Paper.

Halpern, Joseph Y. 2001. "Alternative Semantics for Unawareness,” 37 Games and Economic Behavior 321-339.

Halpern, Joseph Y., and Leandro C. Rêgo. 2012. "Extensive Games with Possibly Unaware Players," Mathematical Social Sciences.

Heifetz, Aviad, Martin Meier, and Burkhard C. Schipper. 2006. "Interactive Unawareness," 130 Journal of Economic Theory 78-94.

Heifetz, Aviad, Martin Meier, and Burkhard C. Schipper. 2008. "A Canonical Model of Interactive Unawareness," 62 Games and Economic Behavior 304-324.

Kahan, Marcel, and Michael Klausner. 1997. "Standardization and Innovation in Corporate Contracting (Or "The Economics of Boilerplate')," 83 Virginia Law Review 713-770.

Kraakman, Reinier H. 1986. "Gatekeepers: The Anatomy of a Third-Party Enforcement Strategy," 2 Journal of Law, Economics, and Organization 53-104.

Krishnan, C. N. V., and Ronald W. Masulis. 2013. "Law Firm Expertise and Merger and Acquisition Outcomes," 56 Journal of Law and Economics 189-226.

Li, Jing. 2006. "Dynamic Games of Complete Information with Unawareness," University of Pennsylvania, Working Paper.

Manns, Jeffrey, and Robert Anderson IV. 2013. "The Merger Agreement Myth," 98 Cornell Law Review 1143-1188.

Okamoto, Karl S. 1995. "Reputation and the Value of Lawyers," 74 Oregon Law Review 15-55.

Priest, George L. 1981. "A Theory of the Consumer Product Warranty," 90 Yale Law Journal 1297-1352.

Ribstein, Larry E. 2010. "The Death of Big Law," 2010 Wisconsin Law Review 749-815.

Schwarcz, Steven L. 2007. "Explaining the Value of Transactional Lawyering," 
12 Stanford Journal of Law, Business \& Finance 486-535.

Schwartz, Alan. 1977. "A Reexamination of Nonsubstantive Unconscionability,” 63 Virginia Law Review 1053-1083.

Smith, Jr., Clifford W., and Jerold B. Warner. 1979. "On Financial Contracting: An Analysis of Bond Covenants," 7 Journal of Financial Economics 117-161.

Sutton, John. 1986. "Non-Cooperative Bargaining Theory," 53 Review of Economic Studies 709-724. 